\title{
The Influence of Railway Bridge Vehicle Vibration on Sand Liquefaction in a Dam Foundation
}

\author{
Donghe $\mathrm{Ma}^{1}$, Xuezhong $\mathrm{Guo}^{2}$, Yanping $\mathrm{Li}^{3}$, \\ Xiaowu $\mathrm{Xu}^{4}$, Ruhui Huang ${ }^{5}$ \\ Academy of science \\ China water northeastern investigation, design \& \\ Research Co., Ltd. \\ Changchun, China \\ 123madonghe@163.com
}

\author{
Fengde Zhang $^{6}$ \\ Hydraulic engineering construction bureau of \\ Heilongjiang Province. \\ Harbin, China
}

\begin{abstract}
Saturated sandy soil liquefaction of a dam foundation caused by vehicle vibration was studied by using the QUAKE/W finite element software combined with a concrete project example. Two high-speed trains were used to simulate vibration under driving conditions. The results showed that foundation soil liquefaction occurred with increased depth and narrowed pile foundation design. When the pile foundation was established throughout the sand into the bedrock, the scope of liquefaction decreased, and the foundation basically remained stable.
\end{abstract}

Keywords- Embankment foundation; Vehicle vibration; Liquefaction ; Finite element

\section{INTRODUCTION}

Many water conservancy projects encounter liquefaction induced by vibration (including earthquakes, vehicle vibration, and so on). Vibration liquefaction directly affects the stability of the foundation of engineering facilities, thus affecting overall engineering safety and reducing the stability of structures. For example, the 1969 Bohai earthquake caused levee segments of the Shandong Yellow River to crack, collapse, and exhibit ground subsidence. Conducting a specific analysis of the engineering foundation vibration liquefaction problem, accurately determining the factors that affect the vibration liquefaction of foundations, and proposing reasonable and effective engineering measures are universal concerns of water conservancy workers, but performing such tasks are difficult because of different engineering geological and operating conditions [1].

Over the years, the understanding of sand liquefaction and its development mechanism has improved significantly, and relevant testing techniques and analysis methods have been perfected gradually. The finite element method (FEM) for the dynamic analysis of soil in particular is a powerful tool for sand liquefaction research. With its unique application in the field of geotechnical engineering, FEM can be widely used because it can handle almost any complex boundary condition, all kinds of nonlinear characteristics of the medium, and the complex form of load. FEM is used for the finite element discretization of the structure formed by the body, instead of the continuum structure, to analyze deformation and stress [2].

\section{STUDY AREA}

The study area is located in the Songhua River in Heilongjiang Province, specifically the levee sections of the railway bridge reconstruction project. The slopes of the railway bridge north shore upstream and downstream are $20.06 \mathrm{~m}$ and $8.24 \mathrm{~m}$, respectively, away from the dam toe. The rebuilding project of the north shore upstream slope is $14.4 \mathrm{~m}$ away from the dam toe, and the downstream slope platform is close to the dam toe. A thicker saturated silty sand layer is present in the upper soil layer of the embankment, and liquid damage may occur with a certain degree of vibration on the silty sand layer. Therefore, to understand and control the effects of train vibration on the stability of the embankment soil mass, preserving the railway bridge is important to ensure embankment safety .

The properties of each soil layer in the study area are as follows: (1) undisturbed soil $\left(\mathrm{Q}_{4}{ }^{\mathrm{ml}}\right)$ : motley composed of silty clay, construction waste, and so on, and is mainly distributed on both sides of the bridge site; $0.8 \mathrm{~m}$ to $4.8 \mathrm{~m}$ thick; (2) silt $\left(\mathrm{Q}_{4}{ }^{\mathrm{al}}\right)$ : tan, primarily celadon; the mineral composition contained mainly quartz and feldspar; the soil is wet to saturated, loose $\sim$ Medium dense, 1.5 to $11 \mathrm{~m} \mathrm{~m}$ thick; level I losse soil; (3) fine sand $\left(\mathrm{Q}_{4}{ }^{\mathrm{a}}{ }^{\mathrm{l}}\right)$ : tan, primarily celadon; the mineral composition is mainly quartz and feldspar; the soil is wet to saturated, loose $\sim$ Medium dense; $1.0 \mathrm{~m}$ to $14.2 \mathrm{~m}$ thick; level I losse soil; (4) medium sand $\left(\mathrm{Q}_{4}{ }^{\mathrm{al}}\right)$ : celadon; the mineral composition is mainly quartz and feldspar; saturated, slightly dense $\sim$ Medium dense Micronesia; $0.7 \mathrm{~m}$ to $11.2 \mathrm{~m}$ thick; level I losse soil (5) coarse sand $\left(\mathrm{Q}_{4}{ }^{\mathrm{al}}\right)$ : celadon; the mineral composition is mainly quartz and feldspar; saturated, slightly dense $\sim$ Medium dense; $1.0 \mathrm{~m}$ to $14.5 \mathrm{~m}$ thick; level I losse soil.

\section{FEM}

\section{A. Initial static analysis}

Geoslope, well-known finite element analysis software for geotechnical engineering, was adopted in this study. The QUAKE/W module in Geoslope provided the parameters of the two kinds of material model, elasticity, and the equivalent elasticity of the two kinds of model. The static 
analysis process sets the linear elastic constitutive model and the material parameters for the constant value and material stress strain elastic relations [3].

1) Meshing and parameter selection: Meshing density should meet the required accuracy and has to be based on the unit grid with two triangle units and six nodes. Meshing density should be highly precise and be capable of simulating any geometry on the slope and wedge area, especially for the transition section. To simulate the real geometry of the state, improve calculation accuracy, and reduce computation time, the triangular element with six nodes is prioritized, the local area is based on the quadrilateral element, and subdivision units total 14632. QUAKE/W requires the following soil mechanics parameters: shear modulus $\mathrm{G}$, elastic modulus $E$ and Poisson's ratio $\mu$, damping ratio, and severe $\gamma$, and $G, \mu, E$ has the following connections, as in (1). The soil mechanics parameters selected were shown in Table 1 .

$$
E=2(1+\mu) G
$$

2) Boundary Condition:The soil is a restrained halfinfinite space from the bottom of the rock mass. Therefore, the model contains a displacement constraint. Displacement constraints are placed on both ends of the boundary conditions for the $\mathrm{x}$ direction, whereas the $\mathrm{y}$ direction is free. Underlying bedrock boundary constraints are set for the $x$ and $y$ directions. The slope is unconstrained, and the plane is free. The $x$ direction is positive, and the slope face is empty in the $y$ direction. The gravity in the opposite direction is positive.

3) Simulation Results:According to the above parameters, such as the grid, borders, and other requirements which are used to establish the finite element model, as shown in Fig. 1.

TABLE I. CALCULATING PARAMETERS

\begin{tabular}{|c|c|c|c|c|c|c|}
\hline NO. & Name & Compaction & $\begin{array}{l}\text { elasticity } \\
\text { modulus } \\
(\mathrm{MPa})\end{array}$ & $\begin{array}{l}\text { Poisson } \\
\text { ratio }\end{array}$ & $\begin{array}{c}\text { saturated unit } \\
\text { weigh } \\
\left(\mathrm{kN} / \mathrm{m}^{3}\right) \\
\end{array}$ & $\begin{array}{l}\text { Damping } \\
\text { ratio }\end{array}$ \\
\hline $4-0$ & Silt & Loose & 6 & 0.25 & 26 & \multirow{10}{*}{0.1} \\
\hline $5-0$ & Fine sand & Loose & 9 & 0.25 & 25.8 & \\
\hline $7-1$ & Coarse sand & $\begin{array}{l}\text { Slightly less } \\
\text { dense }\end{array}$ & 26 & 0.24 & 25 & \\
\hline $5-1$ & Fine sand & $\begin{array}{l}\text { Slightly less } \\
\text { dense }\end{array}$ & 14 & 0.25 & 25.8 & \\
\hline $8-2$ & Medium sand & Medium dense & 31 & 0.2 & 26 & \\
\hline $6-2$ & Medium sand & Medium dense & 30 & 0.23 & 26 & \\
\hline $7-2$ & Coarse sand & Medium dense & 36 & 0.22 & 25 & \\
\hline $9-2$ & $\begin{array}{l}\text { Smooth round } \\
\text { gravel soil }\end{array}$ & Medium dense & 30 & 0.2 & 25 & \\
\hline $3-0$ & Silty clay & Hard plastic & 16 & 0.25 & 19.5 & \\
\hline $4-2$ & silt & Medium dense & 9 & 0.24 & 26 & \\
\hline 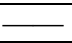 & Concrete pier & - & 32000 & 0.17 & 26.5 & 0.015 \\
\hline
\end{tabular}

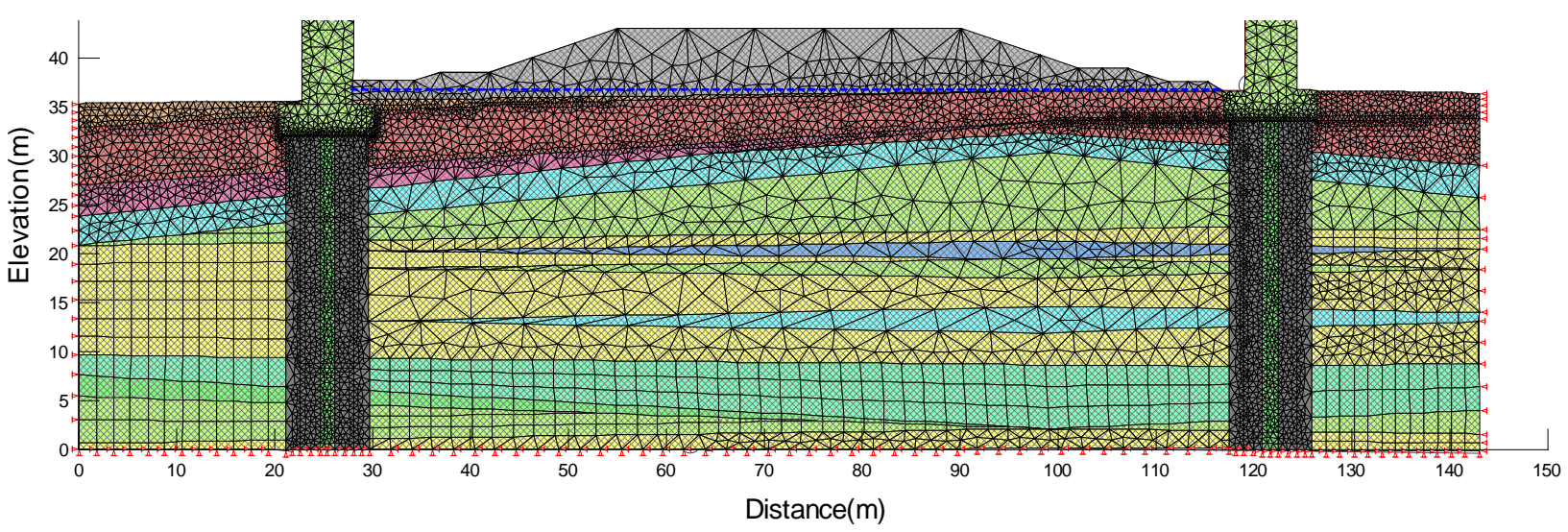

Figure 1. Finite element calculation model 
The results shown that, under the natural state, in which the dam is not subjected to vibration and the groundwater is stable, the linear distribution of pore water pressure increases with depth, and the super static pore water pressure of the soil in the embankment foundation is zero. At the same height, pore water pressures are equal, and the pore water pressure distribution is in the horizontal direction, as shown in Fig. 2.

\section{B. Dynamic Analysis}

The equivalent linear elastic model (Hardin-Drnevich model) was used to conduct the dynamic stability analysis of the dam foundation [4]. In the equivalent linear iteration analysis, the shear modulus, the damping ratio with a change in the shear strain relationship of the experiment curve, and the corresponding equivalent shear strain modulus and damping ratio are used for comparison with the previous calculation which considered the shear modulus and damping ratio. If the result does not satisfy the standard iteration convergence, the shear modulus and damping ratio according to the interpolation must be calculated repeatedly until the unit meets the iterative calculation requirement of all soil standards.

1) Vibration acceleration time history curve:Vehicle vibration acceleration time history curve obtained from the German track interference spectrum excitation was considered for calculating $[5,6]$. The maximum horizontal vibration acceleration was $0.34 \mathrm{~m} / \mathrm{s}^{2}$, and maximum vertical acceleration was $0.14 \mathrm{~m} / \mathrm{s}^{2}$, as shown in Fig. 3 and Fig. 4, respectively.

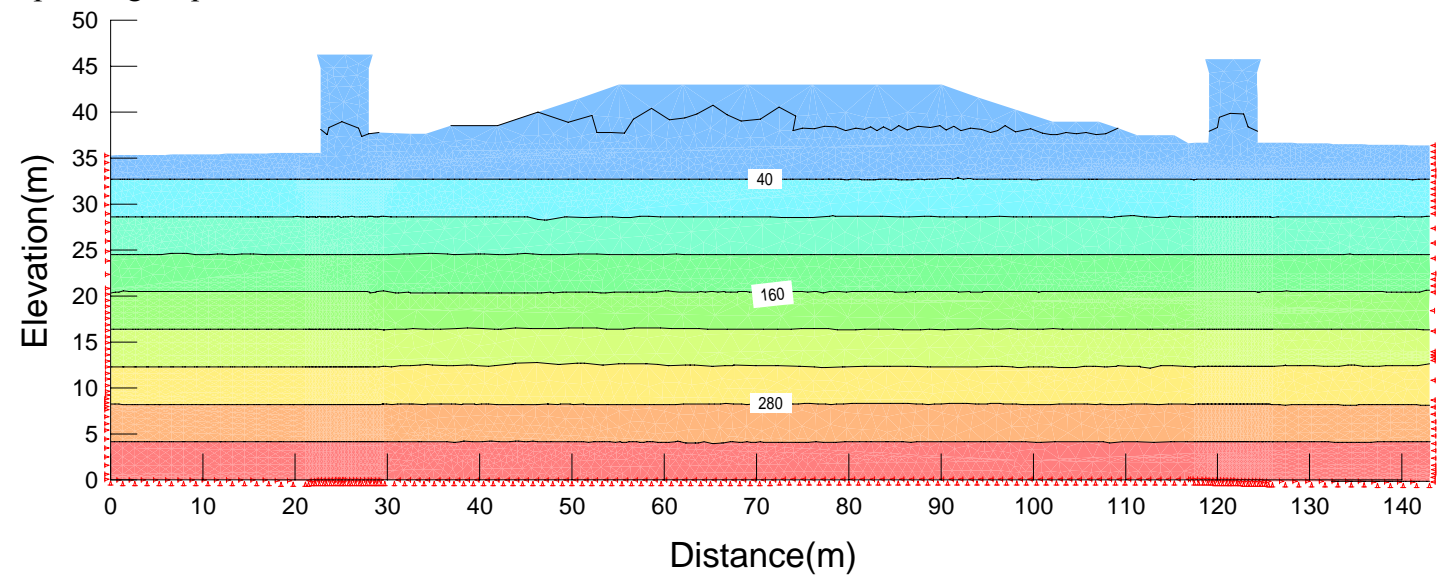

Figure 2. Pore water pressure distribution

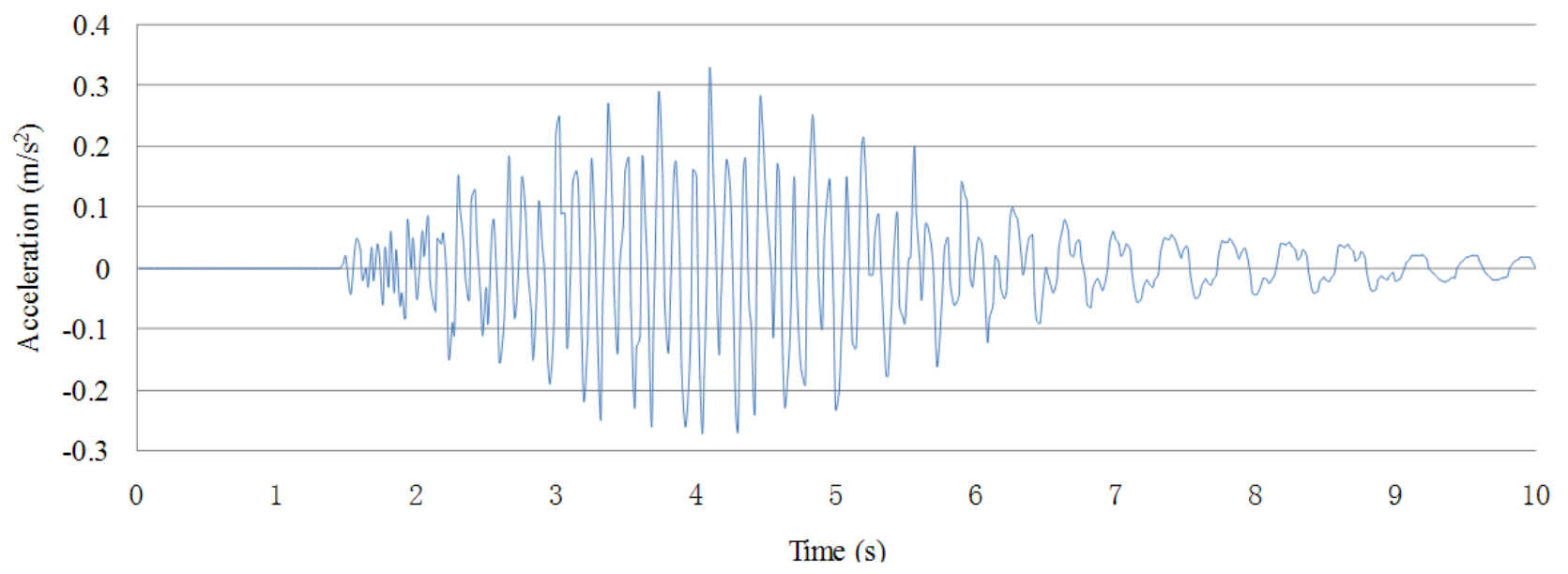

Figure 3. Bridge abutment lateral acceleration time history 


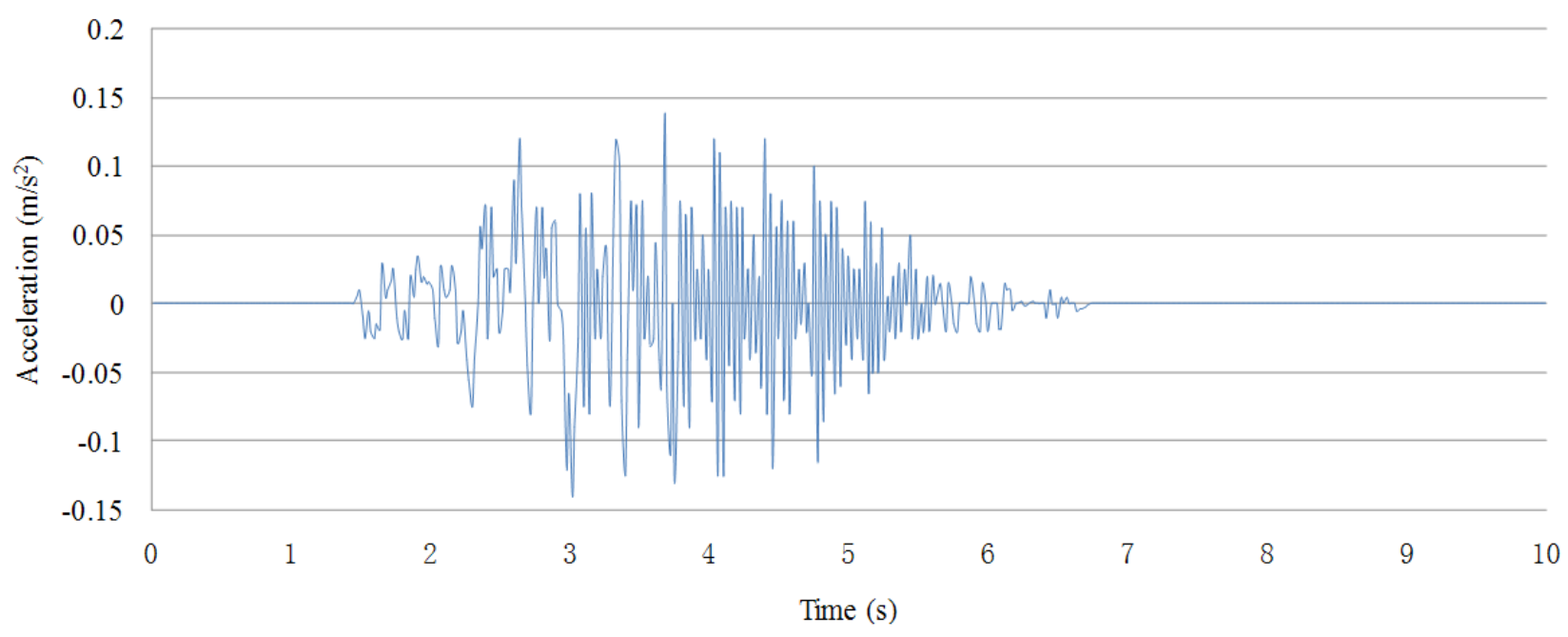

Figure 4. Bridge abutment vertical acceleration time history

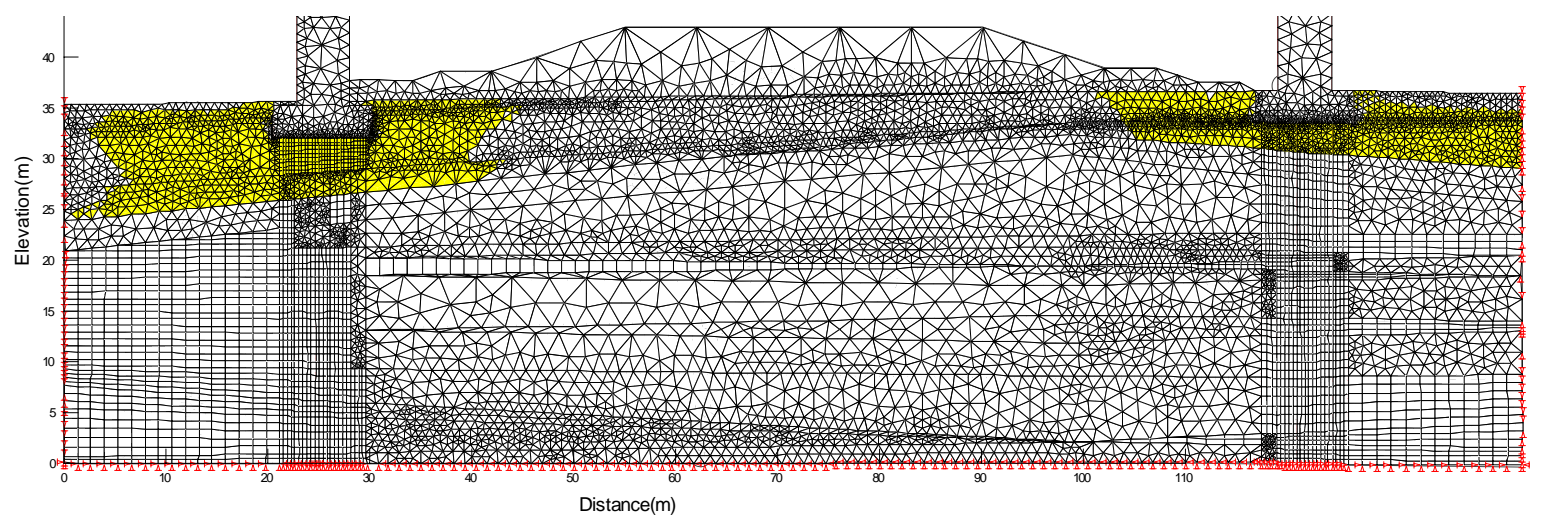

Figure 5. Scope of foundation soil liquefaction without pile

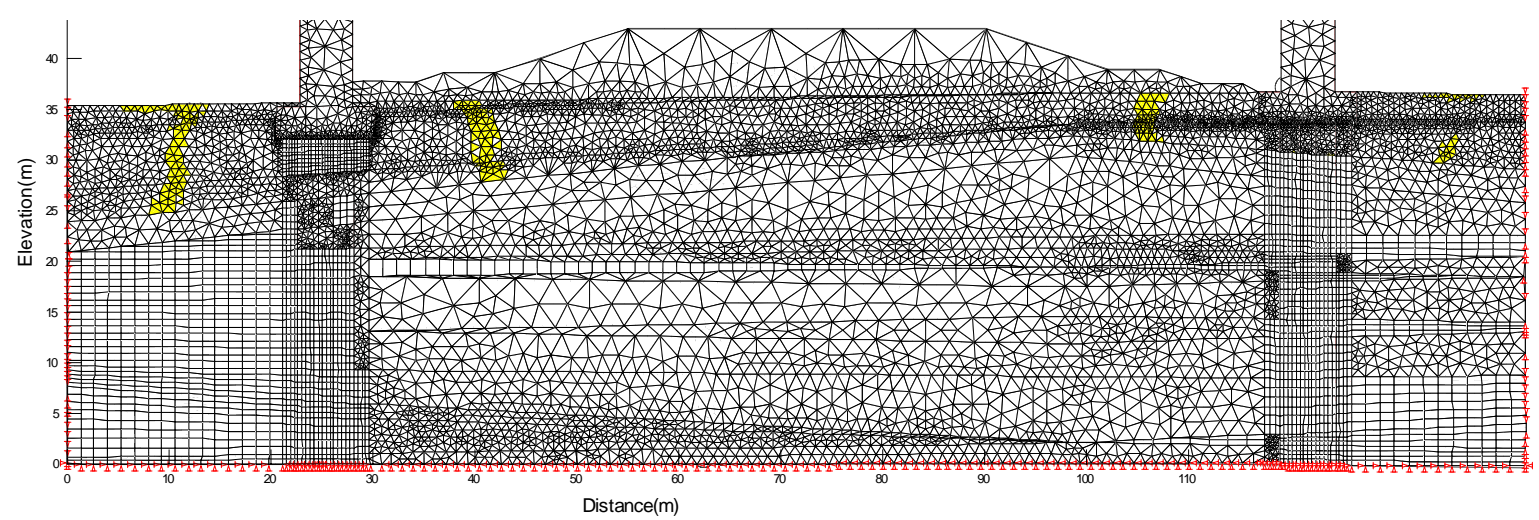

Figure 6. Scope of foundation soil liquefaction with Pile embedment depth to bedrock

2) Simulation Results:The standards for determining soil liquefaction are as follows: dynamic shear stress is greater than the anti-liquefaction shear stress when soil is liquefied; during dynamic calculation, each vibration duration period is divided into 10 periods, with 50 periods for each data set, and an integral step length of $0.02 \mathrm{~s}$; the total duration is $10 \mathrm{~s}$, and the computing time step is 500; and the computation of the lateral vibration time history 
curve of the dynamic calculation model sets two root bridge piers on top of the acceleration boundary.

This design proposal simulated two high-speed trains that reached the two piers at the same time. Caps were placed directly in the sand layer in the dam foundation, and the bottom of the pile is unsupported. The characteristics of soil liquefaction in the embankment foundation are shown in Fig. 5. The soil liquefaction area around the piers was larger. At the pier, the liquefaction reaches down by $6 \mathrm{~m}$ and pushes outward along the axis by approximately $18 \mathrm{~m}$.

With other conditions kept constant, the simulation of pile caps is supported by many piles, and the pile foundation is deep in the bedrock. The characteristics of the soil liquefaction in the embankment foundation are shown in Fig. 6. The simulation results indicate that the liquefied soil ranged outward from the pier around the central axis of $15 \mathrm{~m}$ with a width of approximately $3 \mathrm{~m}$. The soil mass in the embankment foundation produced the law of development because of vibration caused by the bridge piers and piles. Therefore, at a constant vibration acceleration at the top of the piers, the vibration source quality increases with the deepening of the pile foundation, and the surrounding binding force of the embankment foundation soil increases, such that the foundation soil of vibration excitation is inevitably weakened, thereby reducing the liquefaction scope.

\section{CONCLUSIONS}

When a high-speed train travels through a bridge pier, a certain degree of vibration in the bridge piers occurs at a maximum horizontal vibration acceleration of $0.34 \mathrm{~m} / \mathrm{s}^{2}$ and a maximum vertical acceleration of $0.14 \mathrm{~m} / \mathrm{s}^{2}$.

QUAKE/W was adopted to simulate vehicle vibration without the support of piles and pile caps. A large liquefied area appeared in the foundation soil of the levee embankment. The liquefaction depth of the pier was $6 \mathrm{~m}$, pushing outward along the axis by approximately $18 \mathrm{~m}$.

Bridge piers and piles serve as the vibration source. When the vibration acceleration at the top of the piers is constant, the vibration source increases in quality along with the deepening of pile foundation. The surrounding binding force of embankment foundation soil then increases. Therefore, the foundation soil of vibration excitation is inevitably weakened, thus reducing the liquefaction scope. In an embankment, pile caps provide more support in simulation planning design at a depth of $32 \mathrm{~m}$ into the bedrock. The depth of the liquefaction scope of the pile foundation from the pier ringwise around the central axis is $15 \mathrm{~m}$, and the width is only approximately 3 $\mathrm{m}$ in the toe.

\section{REFERENCES}

[1] Zuwen Yan, Jingmei Li, etc. Earthquake under the action of dam foundation soil liquefaction discrimination and dynamic finite element analysis $[\mathrm{J}]$. China rural water and hydropower, 2006, 10: 79-81.
[2] Xiao Zheng, Chunlei Chen, etc. Finite element analysis of dam foundation sand liquefaction under seismic loading [J]. Railway construction, 2009, 10: 73-74.

[3] Dynamic Modeling with QUAKE/W,GeoStudio Tutorials.2004: 71-80.(in Chinese)

[4] Dingyi Xie. Soil dynamics [M]. Xi'an: Xi'an Jiaotong university press, 1988.

[5] Zhimin Ling, Xueqin Cao, etc. Railway vehicle bridge coupling vibration response analysis of high piers of continuous girder Bridges [J]. Journal of railway, 2002, 24(5): 98-101.

[6] Liang Zheng. Large span bridge with high-rise piers train-bridge coupling vibration model test research[D]. Chang'an University, 2011. 